\title{
Análise da vulnerabilidade dos adolescentes à hepatite B em Teresina/PI
}

\author{
Analysis of the vulnerability of adolescents to hepatitis B in Teresina/PI
}

Análisis de la vulnerabilidad de los adolescentes a la hepatitis B en Teresina-PI

Telma Maria Evangelista de Araújo ${ }^{1}$ Khelyane Mesquita de Carvalho², Rebeca Mendes Monteiro³

\begin{abstract}
RESUMO
Os adolescentes fazem parte de grupos com elevada suscetibilidade à infecção pelo vírus da hepatite B em função da adoção de comportamentos de risco. Este trabalho objetivou analisar a vulnerabilidade dos adolescentes à hepatite B. Para isso, realizou-se estudo desenvolvido por meio de inquérito epidemiológico com 196 adolescentes de 14 a 19 anos. Os resultados mostraram que $57,1 \%$ dos adolescentes já haviam iniciado a vida sexual, destes $45,5 \%$ não tinham parceiro(a) estável, 54,5\% pertenciam a faixa etária de 14 a 16 anos, 24,1\% não usavam preservativo nas relações sexuais, 62,8\% referiram não saber da transmissão do vírus da hepatite B e $61,2 \%$ não apresentavam cobertura vacinal contra este agravo. Conclui-se que os adolescentes constituem grupo vulnerável à hepatite $B$, devido a fatores condicionantes e determinantes, tais como desconhecimento sobre a doença, baixa cobertura vacinal, adoção de comportamento de risco e sensação de invulnerabilidade.
\end{abstract}

Descritores: Adolescentes; Hepatite B; Vulnerabilidade; Cuidados de Enfermagem.

\section{ABSTRACT}

Adolescents are part of a group with a high susceptibility to infection with the hepatitis B virus, due to the adoption of highrisk behaviors. This study aimed at analyzing the vulnerability of adolescents to hepatitis B. In order to do so, a study was developed with 196 adolescents between 14 and 19 years of age, utilizing an epidemiological survey. Results showed that $57.1 \%$ of the adolescents were sexually active; $45.5 \%$ of them did not have a stable partner, $54.5 \%$ were aged between 14 and 16 years, $24.1 \%$ did not use a condom during sexual relations, $62.8 \%$ stated they were not aware of the mode of transmission of the hepatitis $B$ virus and $61.2 \%$ had not received the vaccine against this virus. Therefore, adolescents constitute a vulnerable group to hepatitis B, due to conditioning and determinant factors, such as lack of awareness regarding the disease, poor vaccine coverage, adoption of high-risk behaviors and a feeling of invulnerability to the disease.

Descriptors: Adolescent; Hepatitis B; Vulnerability; Nursing Care.

\section{RESUMEN}

Los adolescentes forman parte de los grupos con elevada susceptibilidad a infección por virus de la hepatitis B en función de la adopción de comportamientos riesgosos. Se objetivó analizar la vulnerabilidad de los adolescentes a la hepatitis B. Se realizó el estudio, desarrollado mediante averiguación epidemiológica con 196 adolescentes de 14 a 19 años. Los resultados expresaron que $57,1 \%$ de los adolescentes ya había iniciado su vida sexual; de ellos, 45,4\% no poseía compañero/a estable, $54,5 \%$ tenía entre 14 y 16 años, 24,1\% no utilizaba preservativo, 62,8\% refirió no estar enterado de la transmisión del virus de la hepatitis B y 61,2\% no presentaba cobertura de vacunación contra esta patología. Se concluye en que los adolescentes constituyen un grupo vulnerable a la hepatitis B, debido a factores condicionantes y determinantes, tales como el desconocimiento sobre la enfermedad, baja cobertura de vacunación, adopción de comportamientos riesgosos y sensación de invulnerabilidad.

Descriptores: Adolescente; Hepatitis B; Vulnerabilidad; Atención de Enfermería.

\footnotetext{
1 Enfermeira, Doutora em Enfermagem em Saúde Coletiva. Professora Adjunto da Universidade Federal do Piauí. Teresina, PI, Brasil. E-mail: telmaevangelista@gmail.com.

${ }^{2}$ Acadêmica do curso de graduação em Enfermagem da UNINOVAFAPI. Teresina, PI, Brasil. E-mail: khelyane@uol.com.br.

${ }^{3}$ Enfermeira. Teresina, PI, Brasil. E-mail: rebecammonteiro@hotmail.com.
} 


\section{INTRODUÇÃO}

A hepatite B é uma doença caracterizada por graves consequências ao fígado, podendo levar à falência hepática, cirrose hepática e suas complicações ao hepatocarcinoma (aproximadamente $80 \%$ dos casos de carcinoma hepatocelular em todo o mundo são causados pela infecção crônica por VHB). Tem como agente etiológico o vírus da hepatite B (VHB) e sua origem remonta há vários milênios, em que informações contidas na literatura chinesa faziam referência à ocorrência de icterícia entre sua população há mais de cinco mil anos(1).

A transmissão do vírus da hepatite $B$, segundo o Ministério da Saúde, se faz por via parenteral, e, sobretudo sexual sendo de fácil transmissão devido ao seu poder infectivo, sendo considerada uma doença sexualmente transmissivel que pode ser prevenida através da vacinação, cuja ação é prevenir a doença aguda, impedir a cronificação da hepatopatia e sua evolução para cirrose e/ou hepatocarcinoma e, ainda, contribuir para minimizar a transmissão vertical e imunizar permanentemente as pessoas que não tiveram contato com o vírus (2).

Esta infecção viral continua a ser um importante problema de saúde pública em nível mundial. A Organização Mundial da Saúde estima que cerca de dois bilhões de pessoas já se infectaram pelo vírus da hepatite B, e destes, 350 milhões são portadores crônicos, apresentando alto risco de óbito por cirrose hepática e câncer de fígado. Calcula-se a ocorrência anual de um milhão de mortes ao ano relacionadas à infecção ${ }^{(2-3)}$.

Dados do Ministério da Saúde revelam que os casos confirmados de hepatite B totalizaram 104.454 no período de 1999 a 2010 . A taxa de detecção de casos no país para esse último ano foi de 6,1 por $100 \mathrm{mil}$ habitantes, sendo que as Regiões Sul $(12,8)$ e Sudeste $(9,1)$ apresentaram as mais elevadas taxas. Do total de casos, $71,8 \%$ estão concentrados na faixa etária entre 20 e 49 anos de idade. Segundo o Inquérito Nacional realizado em 2011, o percentual de expostos ao vírus da hepatite B (VHB) foi de 1,1\% na faixa etária de 10 a 19 anos e de $11,6 \%$ no grupo de 20 a 69 anos. As menores prevalências do marcador anti-HBc foram observadas na região Centro-Oeste (4,3\%) e no Distrito Federal (3,0\%), seguidos do Sudeste $(6,3 \%)$. Os níveis mais elevados de exposição ao VHB foram observados nas Regiões Nordeste $(9,13 \%)$, Sul $(9,59 \%)$ e Norte $(10,9 \%)^{(4)}$.

Neste contexto alguns grupos são particularmente suscetíveis ao agente VHB, sejam por condições de saúde que impliquem em transfusões sanguíneas frequentes, atividade dos profissionais da saúde, seja pela adoção de comportamentos de risco como uso de drogas injetáveis ilícitas, múltiplos parceiros sexuais e relações sexuais desprotegidas, comportamento frequente durante o processo de desenvolvimento associado à puberdade.

Os adolescentes têm sido considerados um grupo com risco elevado de exposição ao vírus da hepatite $B$, pois são suscetíveis à pressão negativa de seus pares, sensação de invulnerabilidade e imortalidade, apresentam dificuldades para associar comportamentos de risco atual e consequências futuras. Assim, estudos vêm mostrando um aumento da positividade para o VHB na adolescência que se estende até a idade adulta ${ }^{(5)}$.

Nesta perspectiva, tem-se observado nas últimas décadas a preocupação com o desenvolvimento de estudos que avaliem a vulnerabilidade às doenças sexualmente transmissíveis de grupos populacionais no cenário mundial. As causas de morbimortalidade entre os adolescentes têm sido bastante documentadas, bem como sua associação com o comportamento pessoal ${ }^{(6)}$.

Assim, esta proposta de estudo justifica-se pela produção de informações que possam subsidiar discussões e ações acerca dos fatores de risco para a infecção pelo vírus da hepatite $B$, a que os adolescentes estão expostos, uma vez que a visibilidade no contexto local ainda é pequena, frente à dimensão do problema que representa. Considera-se importante o aumento progressivo de casos confirmados de hepatite $B$ no país, bem como a estabilidade do vírus, variedades nas formas de transmissão e a existência de portadores crônicos permitindo a sobrevida e persistência do VHB na população(4).

Entende-se ainda que o estudo possa contribuir, mais particularmente, para um diagnóstico sobre os possíveis comportamentos de risco dos adolescentes, auxiliando no avanço das políticas públicas que tratam da questão e no envolvimento das instituições de saúde em ações e programas dirigidos à prevenção dessa DST entre adolescentes.

Vale ressaltar, na proposta do estudo, o fato de as políticas socioeconômicas brasileiras, no campo da saúde 
e da educação pública ainda deixarem a desejar e não atingirem de forma satisfatória a grande massa da população no que diz respeito à atenção integral à saúde.

Dessa forma, o estudo pode subsidiar os profissionais de saúde para o desenvolvimento de ações com o propósito de atender o adolescente numa visão biopsicossocial, enfatizando a promoção à saúde, prevenção dos agravos, diagnóstico precoce, tratamento e reabilitação, melhorando a qualidade de vida do adolescente e de sua família. Assim, também se tem a expectativa de levantar dados importantes que possam contribuir de forma loco-regional para a construção de novos estudos a partir da discussão dos achados encontrados neste e fortalecer a linha de pesquisa relacionada à vigilância em saúde no Estado. Para tanto, este estudo objetivou analisar a vulnerabilidade dos adolescentes à hepatite $\mathrm{B}$ em Teresina.

\section{METODOLOGIA}

Trata-se de um estudo descritivo, desenvolvido por meio de inquérito epidemiológico.

A população fonte constituiu-se de adolescentes residentes na área norte de Teresina, regularmente matriculados em escolas da rede municipal. Para tamanho da amostra considerou-se a prevalência nacional de DST na população geral, tomando-se por base $15 \%$, erro tolerável de amostragem de $5 \%$ e um nível de confiança de $95 \%$ totalizando 196 adolescentes ( $n=196)$.

Os dados foram coletados no período de novembro a dezembro de 2010, utilizando-se questionário estruturado, pré-testado, acompanhado do Termo de Consentimento Livre e Esclarecido (TCLE), previamente assinado pelos pais ou responsáveis dos adolescentes. Foram levantados dados socioeconômicos e demográficos, comportamento sexual (início da atividade sexual, número de parceiros e uso de preservativos), uso de álcool e de outras drogas, conhecimento sobre hepatite $B$ relacionados às formas de transmissão e situação vacinal.

Para efeito desse estudo tomou-se a definição de adolescência da Organização Mundial de Saúde (OMS), que considera a etapa da vida compreendida entre a infância e a fase adulta, marcada por um complexo processo de crescimento e desenvolvimento biopsicossocial, compreendendo a faixa etária de 10 a 19 $\operatorname{anos}^{(7)}$.

A parceria na relação sexual foi considerada estável quando envolvia namorado(a), noivo(a) ou marido(esposa) e as demais situações consideradas como parceria não estável. Considerou-se vacinado os adolescentes que apresentavam esquema completo de três doses de vacina contra hepatite $B$.

Os dados foram digitados no programa Microsoft Excel e importados para o programa Statistical Package for the Social Sciences - SPSS (versão 18.0 for Windows), no qual foram tabulados. A análise estatística utilizada foi a descritiva a partir dos percentuais das categorias de respostas das variáveis. Os dados foram explorados por meio das técnicas univariadas e bivariadas, considerando-se média $(X)$, desvio padrão, intervalo de confiança de $95 \%$, mínimo e máximo. O uso do teste Quiquadrado de Pearson $\left(\square^{2}\right)$ com nível de significância $(p<0,05)$, foi utilizado para verificar as possíveis associações entre as variáveis. Entretanto, como este teste não relaciona o tamanho do efeito da associação, utilizou-se V-Cramer, que é uma medida do grau de associação entre duas variáveis categóricas ${ }^{(8)}$.

Para cumprimento dos preceitos relacionados à ética em pesquisa com seres humanos, estabelecidos pela resolução 196/96 do Conselho Nacional de Saúde ${ }^{(9)}$, foi solicitada aos pais ou responsáveis a assinatura do Termo de Consentimento Livre e Esclarecido (TCLE), à exceção dos casados/viúvos/separados, cujos termos foram assinados por eles próprios. Posteriormente o estudo foi aprovado pelo Comitê de Ética em Pesquisa da Faculdade NOVAFAPI (CAAE Nº 0108.0.043.000-10).

\section{RESULTADOS}

A apresentação dos resultados está subdividida em análises univariadas e bivariadas. Nas análises univariadas são apresentadas a descrição da amostra quanto aos aspectos sociodemográficos e econômicos, comportamento sexual, conhecimentos sobre hepatite $B$, formas de transmissão e cobertura vacinal. Nas análises bivariadas, apresentam-se a associação dos fatores de risco para a infecção pelo VHB, com as características sociodemográficos, o uso de bebida alcoólica e outras drogas, comportamento sexual, presença de piercing, tatuagem, cobertura vacinal e o conhecimento sobre a infecção e suas formas de transmissão. A hepatite B foi tomada como variável 
dependente e as demais características como variáveis independentes.

\section{Análise univariada}

Observou-se que $57,7 \%$ da população do estudo (113) tinham idade entre 14 e 16 anos, com média de 16,4 anos, mínima 14 e máxima 19 anos. Quanto ao gênero, 55,6\% são do gênero feminino; $85,7 \%$ residem em Teresina; $82,7 \%$ fazem o ensino médio, $92,9 \%$ estavam solteiros na ocasião da entrevista, sendo que a expressiva maioria $(74,5 \%)$ reside com os pais. Quanto à renda familiar, 46,9\% dos adolescentes informaram ser de um salário mínimo, seguido de dois a três salários $(34,2 \%)$. Dentre a totalidade dos adolescentes pesquisados, 18,9\% (37) já ingressaram no mercado de trabalho, sendo que $62,1 \%$ percebem até R\$ 200,00 mensal, com média igual a R\$234,00. (Tabela 1).

Tabela 1: Caracterização sociodemográfica dos adolescentes do estudo (n=196). Teresina, PI, 2010.

\begin{tabular}{|c|c|c|c|c|c|}
\hline Variáveis & $n(\%)$ & $\bar{x}$ & \pm & IC $95 \%$ & Min-Max \\
\hline Faixa etária & & 16,4 & 1,2 & $16,1-16,5$ & 14-19 \\
\hline 14 a 16 & $113(57,7)$ & & & & \\
\hline 17 a 19 & $83(42,3)$ & & & & \\
\hline \multicolumn{6}{|l|}{ Sexo } \\
\hline Masculino & $87(44,4)$ & & & & \\
\hline Feminino & $109(55,6)$ & & & & \\
\hline \multicolumn{6}{|l|}{ Procedência } \\
\hline Teresina & $168(85,7)$ & & & & \\
\hline Interior do Piauí & $17(8,7)$ & & & & \\
\hline Outro estado & $11(5,6)$ & & & & \\
\hline \multicolumn{6}{|l|}{ Escolaridade } \\
\hline Ensino fundamental & $34(17,3)$ & & & & \\
\hline Ensino médio & $162(82,7)$ & & & & \\
\hline \multicolumn{6}{|l|}{ Situação conjugal } \\
\hline Casado & $10(5,1)$ & & & & \\
\hline Solteiro(a) & $182(92,9)$ & & & & \\
\hline Separada & $02(1,0)$ & & & & \\
\hline Viúva & $02(1,0)$ & & & & \\
\hline Renda familiar & & 2,2 & 1,6 & $1,9-2,4$ & 01-09 \\
\hline 01 salário & $92(46,9)$ & & & & \\
\hline 02 a 03 salários & $67(34,2)$ & & & & \\
\hline 04 a 09 salários & $37(18,9)$ & & & & \\
\hline \multicolumn{6}{|l|}{ Trabalha fora de casa } \\
\hline Trabalha & $37(18,9)$ & & & & \\
\hline Não trabalha & $159(81,1)$ & & & & \\
\hline Renda pessoal ( $n=37)$ & & 234 & 184,3 & $172-295$ & $50-800$ \\
\hline Até 100 reais & $08(21,6)$ & & & & \\
\hline 101 a 200 & $15(40,5)$ & & & & \\
\hline 201 a 300 & $09(24,4)$ & & & & \\
\hline 301 a 800 & $05(13,5)$ & & & & \\
\hline \multicolumn{6}{|l|}{ Mora com } \\
\hline Pais & $146(74,5)$ & & & & \\
\hline Companheiro & $07(3,6)$ & & & & \\
\hline Amigos & $03(1,5)$ & & & & \\
\hline Avós & $22(11,2)$ & & & & \\
\hline Sozinho & $01(0,5)$ & & & & \\
\hline Outros & $17(8,7)$ & & & & \\
\hline
\end{tabular}

Nota-se na Tabela 2 que dos 196 adolescentes estudados, 57,1\% já iniciaram a atividade sexual. Desses, $54,5 \%$ tiveram a primeira relação sexual na faixa etária de 14 a 16 anos. Observou-se que um número significativo de adolescentes que já iniciaram a vida sexual, não tem parceiro estável (45,5\%). Na relação sexual, a maioria dos adolescentes $(75,9 \%)$ referiu o uso do códon. Dos 24,1\% que não utilizam, 29,6\% justificaram o não uso por não ter o preservativo no momento e $29,6 \%$ por não dar tempo de usar, embora 96,4\% já tenham sido orientados sobre a importância e o uso do preservativo. 
Tabela 2: Variáveis relacionadas ao comportamento sexual da amostra ( $n=196)$. Teresina, PI, 2010.

\begin{tabular}{|c|c|c|}
\hline Características & $\mathbf{n}$ & $\%$ \\
\hline \multicolumn{3}{|l|}{ Já teve relação sexual } \\
\hline Sim & 112 & 57,1 \\
\hline Não & 84 & 42,9 \\
\hline Total & 196 & 100 \\
\hline \multicolumn{3}{|l|}{ Idade da primeira relação } \\
\hline 07 a 13 & 33 & 29,4 \\
\hline 14 a 16 & 61 & 54,5 \\
\hline 17 a 19 & 18 & 16,1 \\
\hline Total & 112 & 100 \\
\hline \multicolumn{3}{|l|}{ Parceiro } \\
\hline Casual & 51 & 45,5 \\
\hline Estável & 61 & 54,4 \\
\hline Total & 112 & 100 \\
\hline \multicolumn{3}{|l|}{ Usa preservativo nas relações sexuais } \\
\hline $\operatorname{Sim}$ & 85 & 75,9 \\
\hline Não & 27 & 24,1 \\
\hline Total & 112 & 100 \\
\hline \multicolumn{3}{|l|}{ Motivo de não ter usado preservativo ( $n=27)$} \\
\hline Não tinha preservativo & 08 & 29,6 \\
\hline Não deu tempo de usar & 08 & 29,6 \\
\hline O parceiro não gosta de preservativo & 04 & 14,9 \\
\hline Confia na saúde do parceiro & 02 & 7,4 \\
\hline Outros & 05 & 18,5 \\
\hline Total & 27 & 100 \\
\hline \multicolumn{3}{|c|}{ Já foi orientado sobre a importância e o uso do preservativo } \\
\hline Sim & 189 & 96,4 \\
\hline Não & 07 & 3,6 \\
\hline Total & 196 & 100 \\
\hline
\end{tabular}

Na Tabela 3 pode-se observar que 62,8\% dos adolescentes referiram não saber como se contrai o vírus da hepatite B. Dos 37,2\% que afirmaram conhecer a forma de transmissão, 35,6\% citaram relação sexual, $41,1 \%$ por transfusão sanguínea, $21,9 \%$ acidentes com instrumentos cortantes. Os demais adolescentes que responderam saber sobre a transmissão da hepatite $B$ citaram as seguintes formas, $28,8 \%$ por alimentos, $16,4 \%$ pela água, e 1,4\% por outras formas. Quando questionados a respeito da cobertura vacinal a mesma tabela mostra ainda que $61,2 \%$ dos adolescentes não apresentavam cobertura vacinal contra hepatite B.

Tabela 3: Conhecimento sobre transmissão da hepatite B e situação vacinal ( $n=196)$. Teresina, PI, 2010.

\begin{tabular}{|c|c|c|}
\hline Características & $\mathbf{n}$ & $\%$ \\
\hline \multicolumn{3}{|l|}{ Sabe como contrai hepatite B } \\
\hline $\operatorname{Sim}$ & 73 & 37,2 \\
\hline Não & 123 & 62,8 \\
\hline Total & 196 & 100 \\
\hline \multicolumn{3}{|l|}{ Formas de transmissão da hepatite B } \\
\hline Relações sexuais & & 35,6 \\
\hline Alimentos & & 28,8 \\
\hline Água & & 16,4 \\
\hline Transfusão sanguínea & & 41,1 \\
\hline Acidentes com instrumentos cortantes & & 21,9 \\
\hline Outras formas & & 1,4 \\
\hline Total & 73 & 145,2 \\
\hline \multicolumn{3}{|l|}{ Vacinado contra Hepatite B } \\
\hline Vacinado & 76 & 38,8 \\
\hline Não foi vacinado & 120 & 61,2 \\
\hline Total & 196 & 100 \\
\hline
\end{tabular}




\section{Análises bivariadas}

Dos adolescentes que não usam preservativo nas relações sexuais, $45,5 \%$ encontravam-se a época na faixa etária entre sete a 13 anos, igual percentual encontrouse na faixa de 14 a 16 anos. Os adolescentes de Teresina referiram o maior uso do condón. Os solteiros representam 90,9\% dos que não usam preservativo. Observou-se que o uso foi maior entre aqueles cuja família apresentava renda de dois a três salários. As variáveis, quando associadas, não apresentaram significância estatística ( $p>0,05)$.

Tabela 4: Associação do uso do preservativo com idade da $1^{\text {a }}$ relação e variáveis sociodemográficas ( $n=196)$. Teresina, PI, 2010.

\begin{tabular}{|c|c|c|c|}
\hline \multirow{2}{*}{ Variáveis } & \multicolumn{2}{|c|}{ Uso do preservativo } & \multirow{2}{*}{ p valor } \\
\hline & Sim n (\%) & Não n (\%) & \\
\hline Idade da primeira relação & & & 0,16 \\
\hline 07 a 13 & $23(25,6)$ & $10(45,5)$ & \\
\hline 14 a 16 & $51(56,7)$ & $10(45,5)$ & \\
\hline 17 a 19 & $16(17,8)$ & $02(9,1)$ & \\
\hline Procedência & & & 0,44 \\
\hline Teresina & $78(86,7)$ & $21(95,5)$ & \\
\hline Interior Piauí & $07(7,8)$ & $01(4,5)$ & \\
\hline Outro estado & $05(5,6)$ & & \\
\hline Situação conjugal & & & 0,48 \\
\hline Casado & $08(8,9)$ & $02(9,1)$ & \\
\hline Solteiro/separado & $82(91,1)$ & $20(90,9)$ & \\
\hline Renda familiar & & & 0,54 \\
\hline 1 salário & $29(32,2)$ & $07(31,8)$ & \\
\hline 02 a 03 salários & $31(34,4)$ & $10(45,5)$ & \\
\hline 04 a 09 salários & $30(33,3)$ & $05(22,7)$ & \\
\hline
\end{tabular}

Para verificar a correlação entre as variáveis: idade da primeira relação e renda familiar foi realizado o teste de correlação de Pearson, que demonstra a intensidade da relação estatística, o qual apresentou uma relação positiva e elevada $(r=0,67)$. Portanto, quando ocorreu um aumento da renda familiar, aumentou também a idade da primeira relação $(p<0,01)$. (Gráfico 1).

Gráfico 1: Diagrama de dispersão entre renda familiar e idade da primeira relação. Teresina, PI, 2010.

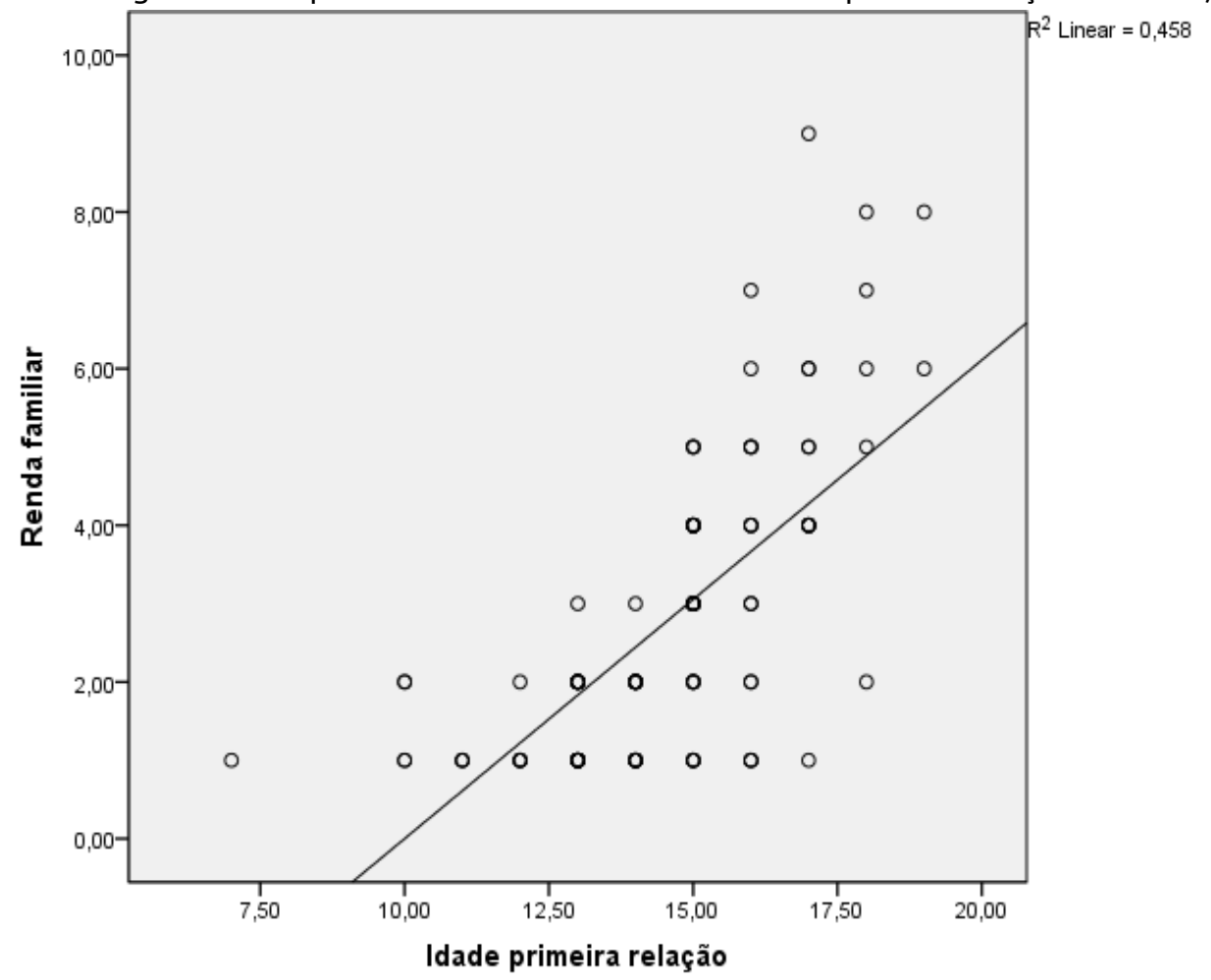


A Tabela 5 demonstra a associação feita entre cobertura vacinal, dados sociodemográficos e fatores de risco para hepatite $B$. Observou-se que dentre os adolescentes que não apresentaram cobertura vacinal para hepatite $B, 52,5 \%$ são do sexo feminino, $56,7 \%$ pertencem a faixa etária de 14 a 16 anos, e 54,2\% já têm vida sexual ativa, dos quais $18,5 \%$ não usam preservativos na relação sexual. Além disso, é importante destacar também, que $57,5 \%$ dos que responderam não saber como se contrai a hepatite $B$, estavam sem cobertura vacinal e, dos que consomem bebida alcoolica, 78,3\% também não apresentaram a proteção conferida pela vacina. O conhecimento sobre a transmissão da hepatite B apresentou significância estatística quando associado a cobertura vacinal $(p<$ 0,04; V Cramer= 0,15).

Tabela 5: Associação entre a cobertura vacinal, dados sociodemográficos e fatores considerados de risco para hepatite B. Teresina, PI, 2010.

\begin{tabular}{|c|c|c|c|c|}
\hline \multirow[b]{2}{*}{ Variáveis } & \multicolumn{4}{|c|}{ Cobertura vacinal contra hepatite B } \\
\hline & $\begin{array}{c}\text { Sem Cobertura n } \\
\text { (\%) }\end{array}$ & $\begin{array}{c}\text { Com cobertura completa n } \\
(\%)\end{array}$ & $\begin{array}{c}\mathbf{p} \\
\text { valor }\end{array}$ & $\begin{array}{c}\mathbf{V} \\
\text { Cramer }\end{array}$ \\
\hline Sexo & & & 0,27 & \\
\hline Masculino & $57(47,5)$ & $30(39,5)$ & & \\
\hline Feminino & $63(52,5)$ & $46(60,5)$ & & \\
\hline Faixa etária & & & 0,72 & \\
\hline 14 a 16 & $68(56,7)$ & $45(59,2)$ & & \\
\hline 17 a 19 & $52(43,3)$ & $31(40,8)$ & & \\
\hline Procedência & & & 0,23 & \\
\hline Teresina & $100(83,3)$ & $68(89,5)$ & & \\
\hline Interior Piauí/outro estado & $20(16,7)$ & $08(10,5)$ & & \\
\hline Situação conjugal & & & 0,55 & \\
\hline Casado & $07(5,8)$ & $03(3,9)$ & & \\
\hline Solteiro/separado & $113(94,2)$ & $73(96,1)$ & & \\
\hline Já teve relação sexual & & & 0,29 & \\
\hline Sim & $65(54,2)$ & $47(61,8)$ & & \\
\hline Não & $55(45,8)$ & $29(38,2)$ & & \\
\hline $\begin{array}{l}\text { Usa camisinha nas relações sexuais } \\
(n=112)\end{array}$ & & & 0,71 & \\
\hline $\operatorname{Sim}$ & $53(84,5)$ & $37(78,7)$ & & \\
\hline Não & $12(18,5)$ & $10(21,3)$ & & \\
\hline Sabe como contrai Hepatite B & & & 0,04 & 0,15 \\
\hline Sabe & $51(42,5)$ & $22(28,9)$ & & \\
\hline Não sabe & $69(57,5)$ & $54(71,1)$ & & \\
\hline Escolaridade & & & 0,10 & \\
\hline Fundamental & $25(20,8)$ & $09(11,8)$ & & \\
\hline Médio & $95(79,2)$ & $67(88,2)$ & & \\
\hline Uso de bebida alcóolica & & & 0,74 & \\
\hline $\operatorname{Sim}$ & $94(78,3)$ & $58(76,3)$ & & \\
\hline Não & $26(21,7)$ & $18(23,7)$ & & \\
\hline Usou droga & & & 0,08 & \\
\hline Sim & $26(21,7)$ & $09(11,8)$ & & \\
\hline Não & $94(78,3)$ & $67(88,2)$ & & \\
\hline Tatuagem & & & 0,80 & \\
\hline Sim & $14(11,7)$ & $08(10,5)$ & & \\
\hline Não & $106(88,3)$ & $68(89,5)$ & & \\
\hline Piercing & & & 0,23 & \\
\hline $\operatorname{sim}$ & $12(10,0)$ & $04(5,3)$ & & \\
\hline Não & $108(90,0)$ & $72(94,7)$ & & \\
\hline
\end{tabular}

\section{DISCUSSÃO}

A expressiva maioria dos adolescentes estudados pertencia a famílias de baixa renda, (renda familiar de até um salário mínimo) fato importante, uma vez que de acordo com o Ministério da Saúde ${ }^{(4)}$, a região Nordeste apresentou uma maior probabilidade de exposição ao VHB para indivíduos com piores condições econômicas. Na sequência observou-se predominância da faixa etária de 14 a 16 anos, sexo feminino cursando ensino médio. 
Em relação ao sexo de maior exposição, destaca-se o masculino com as maiores taxas de incidência (54,3\%).

Dos 196 adolescentes inquiridos, mais da metade já havia iniciado a atividade sexual e tiveram a primeira experiência na faixa etária de 14 a 16 anos. Em estudo realizado no Rio Grande do Sul(10), a média de idade da primeira relação sexual foi de 16,8 anos. Em Bragança(11), dados semelhantes foram encontrados, uma vez que a média de idade registrada do início da prática sexual foi de 17,5 . Constataram na região metropolitana de São Paulo(12) que a media de idade da primeira relação foi de 16,7 anos para os homens e 19,5 anos para as mulheres.

Isso demonstra uma alteração significativa na tomada de decisão, uma vez que neste estudo meninos e meninas relataram iniciar a atividade sexual na faixa etária de 14 a 16 anos. É importante destacar que, ao se comparar os estudos, observou-se, atualmente, o início da atividade sexual cada vez mais cedo para ambos os sexos, desacompanhado da responsabilidade social que tem seu início cada vez mais tardio, aumentando assim a susceptibilidade dos adolescentes às DST's.

No Rio Grande do Sul 32,7\% dos adolescentes entrevistados relataram um número de dois ou mais parceiros nos últimos 12 meses o que caracteriza relação instável(10), enquanto que no presente estudo o percentual de relação sexual instável entre os adolescentes foi superior, totalizando $45,5 \%$. No tocante ao uso de preservativo, 56,3\% relataram usá-lo pelo menos nas três últimas relações ${ }^{(10)}$, enquanto que estudo realizado em Bragança(11) $54,5 \%$ dos adolescentes relatam o não uso, demonstrando a vulnerabilidade do grupo estudado, uma vez que segundo o inquérito nacional sobre hepatites virais, desenvolvido pelo Ministério da Saúde(4) em 2011, a relação sexual desprotegida foi a primeira causa de fonte provável de infecção pelo vírus da hepatite $B$ neste ano. É importante mencionar que o resultado do citado inquérito ainda apontou uma prevalência 10 vezes maior na população jovem, com destaque para a região Nordeste.

Dentre os adolescentes que não fazem uso do preservativo a alegação foi não tê-lo no momento do ato sexual. Resultado semelhante foi identificado em Bragança(11) onde $24,4 \%$ referiram o não uso pelo mesmo motivo. Enquanto $54,5 \%$ apostam na confiança depositada no parceiro(11), no presente estudo essa porcentagem caiu significativamente para $7,4 \%$.
Pesquisa no Piauí(13) revelou que o uso do condón na primeira relação sexual é frequente. Entretanto, apresenta descontinuidade e negligência. Esse fato chama a atenção para a relevância social que tem e a importância da família, da escola e dos serviços de saúde, no que diz respeito à orientação desses adolescentes antes de iniciar suas atividades sexuais, para que usem um método que faça a prevenção tanto das DSTs quanto de uma gravidez indesejada. Assim, se faz necessária além da orientação, a oferta de insumos de forma contínua, sistemática e planejada, pelos serviços de saúde, para efetivar a prevenção.

É importante destacar que mesmo o conhecimento correto sobre o uso do preservativo não é suficiente para desencadear uma atitude favorável e uma prática positiva, o que demonstra a necessidade de reforçar a orientação contínua para que os adolescentes tenham uma vida sexual livre de riscos e consequentemente saudável.

Ao cruzar os dados da renda familiar e a idade da primeira relação sexual, observa-se que quanto menor a renda mais cedo acontece a primeira relação sexual. Esses dados podem ser decorrentes da cobrança da sociedade nas classes mais elevadas e ao maior nível de escolaridade. Estudo(14) afirma que jovens de classes sociais mais favorecidas postergam o início de sua vida sexual e usam mais proteção porque têm acesso à informação e aos insumos.

A maioria dos participantes não soube informar como se contrai a hepatite $B$, demonstrando que $O$ pouco conhecimento se constitui em um dos principais fatores de risco para a infecção no grupo estudado. Esses dados são compatíveis com resultados encontrados em Santa Catarina(15), onde 76,9\% dos adolescentes estudados não conheciam nenhuma forma de transmissão ou informaram respostas incorretas como picada de mosquito, saliva e espirro, mostrando que os adolescentes não identificam a hepatite $B$ como uma doença que pode ser transmitida pela relação sexual.

Os adolescentes quando abordados sobre as fontes de informações destacaram por ordem de preferência as revistas $(98,2 \%)$ e as conversas informais com os amigos ou desconhecidos (97,5\%) por ficarem mais descontraídos, sugerindo uma fonte de informação limitada e inadequada ${ }^{(11)}$. 
O pouco conhecimento sobre os modos de transmissão da hepatite $B$, não é restrito apenas aos adolescentes. Ao analisarem o controle de infecção pelo VHB por manicures, pedicures e podólogos em São Paulo(16), constataram que $72 \%$ desses profissionais não sabiam as formas de transmissão da doença. No Piauí(17) percentual muito expressivo (44,6\%) foi encontrado entre manicures, pedicures e pedólogos que não souberam relatar nenhuma forma de transmissão do VHB. Corrobora também esta afirmação estudo realizado com caminhoneiros de rota longa que trafegavam por Teresina(18), no qual $72,1 \%$ deles não tinham conhecimento sobre hepatite $B$, reforçando de maneira relevante o desconhecimento da infecção pelo VHB e suas formas de transmissão, em populações distintas estudadas.

No que se refere à cobertura vacinal, $61,2 \%$ foram identificados como suscetíveis à hepatite $B$ por não comprovarem imunidade contra essa infecção. Em Teresina no ano de 2008, apenas 27,2\% dos adolescentes entrevistados completaram o esquema vacinal, evidenciando baixa cobertura(19), quando relacionado ao preconizado pelo Ministério da Saúde que é $95 \%$.

Os adolescentes sabem muito pouco sobre a vacinação em geral, e em particular sobre a vacina contra a Hepatite B. Apresentam baixos níveis de percepção da suscetibilidade e gravidade da doença, adotam comportamentos de alto risco de contaminação, tais como atividade sexual sem proteção, uso de piercing e tatuagens, tornando-se mais vulneráveis à doença ${ }^{(20)}$. Na avaliação da baixa cobertura vacinal destacam-se as oportunidades perdidas de vacinação, uma vez que 92,7\% dos adolescentes procuram o serviço de saúde e por motivos diversificados somente $40,1 \%$ têm acesso as informações sobre vacina o que demonstra que os profissionais de saúde não solicitam ou não observam o cartão de vacina dos adolescentes ${ }^{(19)}$.

No que diz respeito às características relacionadas ao uso de álcool e drogas, pode-se observar que $77,6 \%$ dos adolescentes já fizeram uso de bebida alcoólica e $17,9 \%$ de outros tipos de drogas, constituindo fator de risco quando associado ao sexo por tornar os usuários mais expostos à infecção por conta do êxtase, diminuição do raciocínio, aumento do número de parceiros sexuais e do sentimento de invulnerabilidade.
Destaca-se o uso de bebida alcoólica na última relação sexual em $10,7 \%$ dos 513 adolescentes estudados no Rio Grande do Sul(10). Em Bragança(11) identificou-se que do total de adolescentes entrevistados que já iniciaram a vida sexual, 40,5\% o fizeram sob o efeito de álcool, enquanto que 7,8\% sob efeito de outras drogas.

Outro fator de risco encontrado foi o uso de tatuagens e piercing, por causar ferimentos nos locais de implantação. Em Goiânia o uso do "body" piercing mostrou-se fator importante para infecção pelo VHB, com 3,2 vezes mais de probabilidade ${ }^{(5)}$.

Este estudo mostrou que os adolescentes representam um grupo de alta suscetibilidade ao uso de drogas, o que somado a multiplicidade de parceiros, fazem deles um grupo vulnerável ao aparecimento de agravos, especialmente às doenças sexualmente transmissíveis e entre elas, a Hepatite B.

\section{CONCLUSÃO}

Os resultados desta investigação reforçaram a concepção de que os adolescentes compõem um grupo vulnerável às DSTs, não só pelo fato de um percentual significativo não fazer uso do preservativo ou iniciarem precocemente a atividade sexual, mas também pelas questões socioeconômicas e educacionais estarem atreladas ao problema.

O estudo permitiu observar a carência de informações dos adolescentes relacionada ao conhecimento sobre Hepatites B e a respectiva vacina. Além dos fatores citados, também se constituem como fatores de risco, a presença de piercings, tatuagens, consumo de bebida alcoólica e o uso de outras drogas.

No tocante à imunização, observou-se a baixa cobertura vacinal dos adolescentes, mesmo sendo o grupo em estudo, considerado prioritário pelo Programa Nacional de Imunização, evidenciando o leque de dificuldades e/ou carência de propagação das informações referentes à importância da imunização. Vale destacar que o estudo teve como limitação o fato de nem todos os adolescentes portarem o cartão de vacina na ocasião da coleta de dados, não podendo ser considerada a resposta verbal devido a falta de confiabilidade.

Os resultados dessa investigação apontam para a necessidade de maiores investimentos públicos na prevenção da Hepatite B na população de adolescentes, 
principalmente para os de baixa renda, como os deste estudo, que apresentam condições sociais que parecem favorecer a disseminação viral.

Assim, é notório que o profissional de saúde, em especial os enfermeiros, influencie diretamente na transformação desse quadro, tendo como principal instrumento de trabalho as ações de educação em saúde, enfocando a saúde sexual e reprodutiva juntamente com as entidades sociais e, desse modo, esclarecer dúvidas com vistas a promoção da sexualidade de maneira natural e livre de comportamentos de risco.

2009 [cited 2011 may 20];38(3):155-63. Available from:

http://www.artigonal.com/ensino-superior-artigos/o-conhecimentodos-academicos-de-enfermagem-sobre-as-hepatites-4534043.html 16. Oliveira ACDS, Focaccia R. Survey of hepatitis B and C infection control: procedures at manicure and pedicure facilities in São Paulo, Brazil. Braz J Infect Dis. [Internet]. 2010 [cited 2011 May 20];14(5):502-07. Available from: http://www.scielo.br/pdf/bjid/v14n5/v14n5a13.pdf

17. Abreu AKC, Moreira CMN, Cavalcante DGL. Cobertura vacinal e fatores de risco para a hepatite $B$ entre manicures e podólogos em Teresina- PI [monography]. Teresina: Departamento de Enfermagem/ NOVAFAPI; 2009.

18. Araújo TME, Santos AS, Leite IRL, Carvalho KM, Monteiro RM, Silva

NA. Vulnerabilidade dos caminhoneiros que trafegam por Teresina à infecção pelo vírus da hepatite B. Rev Interdisciplinar [Internet]. 2010 [cited 2011 mar 1];3(1):29-33. Available from:

http://www.primeiraimagem.com.br/novafapi/rev int.html 19. Araújo TME, Carvalho AMC. Análise dos fatores associados à cobertura vacinal contra hepatite B em adolescentes. Rev Acta Pau Enf. [Internet]. 2008 [cited 2011 may 20];23(6):796-802. Available from: http://www.scielo.br/pdf/ape/v23n6/13.pdf

20. Araújo TME, Sá LC, Silva AAS, Costa JP. Cobertura vacinal e fatores relacionados à vacinação dos adolescentes residentes na área norte de Teresina/PI. Rev. Eletr. Enf. [Internet]. 2010 [cited 2010 dec 03];12(3):502-10. Available from:

http://www.fen.ufg.br/revista/v12/n3/v12n3a13.htm.doi:10.5216/re e.v12i3.6934

Artigo recebido em 05/07/2011. Aprovado para publicação em 06/06/2012. Artigo publicado em 31/12/2012. Horta BL. Comportamento sexual de risco: fatores associado
número de parceiros sexuais e ao uso de preservativo em adolescentes. Ciênc. saúde coletiva [Internet]. 2010 [cited 2011 may 20]; 1149-58. Available from:

http://www.scielosp.org/pdf/csc/v15s1/023.pdf 11. Ribeiro MIB, Fernandes AJG. Comportamentos sexuais de risco em estudantes do ensino superior público da cidade de Bragança. Rev. Psicologia, saúde \& doenças [Internet]. 2009 [cited 2011 may 20 ];10(1):99-113. Available from: http://www.scielo.oces.mctes.pt/pdf/psd/v10n1/v10n1a08.pdf 12. Martins LBM, Costa-Paiva LHS, Osis MJD, Sousa MH, Pinto-Neto AM, Tadini V. Fatores associados ao uso de preservativo masculino e ao conhecimento sobre DST/AIDS em adolescentes de escolas públicas e privadas do Município de São Paulo, Brasil. Cad. Saúde Pública [Internet]. 2006 [cited 2011 may 20]; 22(2):315-23. Available from: http://www.scielo.br/pdf/csp/v22n2/09.pdf

13. Mendonça RCM, Araújo TME. Métodos contraceptivos: a prática dos adolescentes das Escolas Agrícolas da Universidade Federal do Piauí. Esc. Anna Nery [Internet]. 2009 [cited 2011 june 05]; 13(4):863-71. Available from:

http://www.scielo.br/pdf/ean/v13n4/v13n4a24.pdf 14. Villela WV, Doreto DT. Sobre a experiência sexual dos jovens. Cad. Saúde Pública [Internet]. 2006 [cited 2011 may 20]; 22(11):2467-72. Available from:

http://www.scielo.br/pdf/csp/v22n11/21.pdf

15. Livramento A, Cordova CMM, Spada C, Treitinger A. Avaliação do nível de conhecimento de adolescentes a respeito da transmissão e prevenção das hepatites B e C. Rev de Patologia Tropical [Internet]. 